\title{
THE ROLE OF INTERINSTITUTIONAL PARTNERSHIPS IN INTERNATIONAL RELATIONS: THE CASE OF EDUCATIONAL POLICIES
}

\author{
Albert Andrei Craiu, PhD student \\ National University of Political Studies and Public Administration \\ Bucharest/Romania \\ craiualbert@gmail.com
}

\begin{abstract}
The theme that I have chosen for that article is at the crossroads of public policies, educational policies and international relationships. It relies in the assumption that is not possible to have public policies at national level if they are not in consistent relation with international regulations, eg. at the European level.

Therefore, along of this study, I will try to give a retrospective look at the measures implemented by Romania in the fields of education and youth at international, European and national levels, in order to have to meet the overall orientations of the educational system to the ideal one. To accomplish this, the paper aims to meet the following objectives to identify the changes at international, European and Romanian levels in the fields of education and youth from their mentioning in the official documents of the European Union. I will also try to identify and analyse projects that have had a major impact in both areas through the achievement of the objects pursued at the time of their development and various levels of implementation.

The Lisbon Strategy, adopted in 2000 and revised in 2005, has as a common goal the development of the European Union as a competitive, dynamic, knowledgebased, global economy capable of sustainable economic growth with a
\end{abstract}


significant increase in the number and quality of jobs available work, as well as greater social cohesion. The education objectives provided for a substantial increase in public spending in this area, the promotion of lifelong learning, the adaptation of basic skills to the needs of the knowledge society, and better recognition of qualifications. With the 2005 Lisbon Strategy Review, education and training have been among the priority areas of the European Union, emphasizing once again the importance of developing human capital as the main asset of Europe.

This is one of the European orientations for policy in education. I will try to find and explain in this article some international directions for policy in education. I will also try to talk about which are the main issues of international education, among which an interesting subject is that of equality of educational opportunities.

\section{Keywords}

Education, educational policy, Erasmus programme, international relationships, interinstitutional partnerships, public policies

\section{INTRODUCTION: EDUCATION, AS THE KEY FOR SOCIAL CHANGE}

Education is that human action that influence, thers behaviour, faster personalities and creates a direction of social development. Over time, more philosophers, writers and visionaries have defined education according to the period in which they lived and knew it. At the same time, education is directly related to culture, and this is essential for those who have tried to define it. To mention only the definition of Plato, who says "education is the art of shaping good skills or developing native skills for the virtues of those who have them", modern states gives a key role of education in overall development and social chance processes. This is particularly the case for Romania, an European Union member facing multiple challenges and asking at a succesfull integration with the European legislation. 
In this request, National Education Law no. 1/2011 provides the legal framework for exercising the fundamental right to education under the authority of the Romanian state. The law regulates the structure, functions, organization and functioning of the education system. It is a basic reference for all efforts devoted to human capital development and social chances. At the same time, we can also analyse it as a document of government educational policy. It is essential that public and educational policies stem from a partnership with civil society, representative associations and trade unions.

An interesting indicator is represented by the evolution of the state's role in the management of educational problems. Prior to 1989, the state party and its ideology held the absolute monopoly on educational institutions, which were state property, without acknowledging the contributions of other stakeholders. In fact, education was an instrument of mass indoctrination, taking into account the fact that teachers and pupils were not free to choose the learning methods or the content of the school curriculum, and after graduation, the students were obliged to engage in jobs designated by the state.

Any transition period, by its evolutionary nature, involves a starting point, a target and a duration. The first and second components are quite precise; the first is the abolition of the totalitarian regime through the 1989 revolution, and in terms of objectives, it is easy to understand that it is aimed at achieving a democratic state and a market economy. The last component and maybe the one that has the decisive role in embracing the largest political population in the population depends on the real circumstances of different states. Thus, in a comparative analysis, Dariusz K. Rosati (1998) estimated the duration of the post-communist transition to about 10 years for the Czech Republic and Slovenia and about 60 years for Romania and Bulgaria (Rosati 1998).

\subsection{Overview of the Romanian education.}

To understand the challenges and the recent efforts by the Romanian society $\mathrm{i}$ will make use of some comparable statistical indicators. This will help us to have a clearer picture of the Romanian educational system within a wider context. 
The share of education spending in total public spending is about $5 \%$ in the EU27 (the highest level being in Denmark, 7\%), while in Romania this percentage is below $3 \%$.

Most students in Central and Eastern Europe are enrolled in public education institutions (more than $98 \%$ in Romania, Lithuania and Croatia), although between 2000 and 2009, the percentage of pupils studying in private institutions doubled in these countries. On average, $14 \%$ of pupils in primary, secondary and high school education are enrolled in private education institutions in the EU-27 (the highest percentage being in Belgium, more than 40\% in Spain and France being $21 \%$, and in the UK $15.8 \%$ ).

The birth rate in the European Union has a downward trend, materialized in the number of the school population. Compared with the demographic decline in Western Europe (with an average fertility rate of 1.5), eastern European countries do not help to improve the overall demographic balance as they face their own decline (the average fertility rate is 1.3) aggravated by massive migration, especially among the young population (The European Semester).

The share of the 18-24 years old population with average education is, on average, $10 \%$ for the EU-27, with large variations in Central and Eastern Europe: $4.8 \%$ in Slovenia and the Czech Republic, compared to 19, 5\% in Latvia, $21 \%$ in Bulgaria and $23.3 \%$ in Romania.

The average duration of formal education in Eastern European countries is slightly below the EU-27 average around 17.2 years.

The percentage of scientists and engineers trained in higher education institutions in Central and Eastern Europe (CEE) is similar to the average in Western Europe, around $10 \%$, but at least $1 / 3$ of those in Eastern European countries emigrate.

Foreign students enrolled in tertiary education (ISCED 5 and 6), as a percentage of total pupils, are much lower in Central and Eastern Europe: $0.1 \%$ in Bulgaria and Latvia, $0.2 \%$ in Slovenia and Estonia, compared to 2.3\% EU average.

Eastern European countries are less prepared for multiculturalism: in 2010, the proportion of the population born abroad was between $10 \%$ and $20 \%$ in the EU27 , but below $2 \%$ in the CEE. Instead, ECE young people, in particular as a means of academic mobility and emigration, are making more efforts to learn 
languages: $99.4 \%$ in Romania and $100 \%$ in Estonia, compared to an average of $85 \%$ in the EU- 27.

The share of education spending in total public spending is about $5 \%$ in the EU27 (the highest level being in Denmark, 7\%), while in Romania this percentage is below $3 \%$.

Most students in Central and Eastern Europe are enrolled in public education institutions (more than $98 \%$ in Romania, Lithuania and Croatia), although between 2000 and 2009, the percentage of pupils studying in private institutions doubled in these countries. On average, $14 \%$ of pupils in primary, secondary and high school education are enrolled in private education institutions in the EU-27 (the highest percentage being in Belgium, more than 40\% in Spain and France being 21\%, and in the UK 15.8\%) (Ministry of Educations statistics 2016). In the early 1990s, the objectives of the transition process were vaguely focused on two major priorities: democracy and market economy. Even the most optimistic analysts have not been able to foresee the actual implications for membership of the European Union. All of this data is closely related to the international situation, with the European Union being an integral part of the world.

International relations are based on structured partnerships on democracy and market economy. In any system, the organization of the state and the economic part are domains of interes. In turn, education has always been a strong point in international relations. It is said that one society can develop without education, which is the main scientific and cultural basis of humanity.

\section{PUBLIC POLICIES AND NEOINSTITUTIONALISM}

Neoinstitutionalism, a stream of applications in all public policies, helps us move closer to the concrete case of interinstitutional partnerships. He includes more independent theories and is part of the "New Public Management" movement, as it was named Christopher Hood in 1991. Since the 1960s and 1970s, under the impact of repeated crises, Walfare State has been criticized for inefficient resource management, for climbing on a hyerarchical management 
style promoted by Max Weber. He has supported this model model in the 19th century, which emphasized bureaucratic hierarchy, authority and loyalty, thereby favoring institutional sclerosis, social dependence and corruption. As a result, in the 1970s, on the backdrop of the reforms initiated by former British Prime Minister Margaret Thatcher, heavily criticized and challenged reforms nowadays, some principles and methods of the private sector have been introduced in public management efficiency, competition, demand-based supply, monetary control, the latter explained by the fact that money controls the service.

The old Christian public service landmarks, theorized by Max Weber, including the separation of administration politics, the civil servant status, the prevalence of citizen's interests, were complemented by the idea of competition and profit, the use of performance indicators and external evaluations, private sector in the management of public resources.

Even though this trend has been mitigated since the economic crisis of 2008, when the state was rediscovered, becoming the job saver, taking on a large part of the debt generated by the private sector, many of the methods and principles of neoliberal origin were maintained because they offered better solutions than the bureaucratic state. They have been institutionalized and have become current practices in various sectors, including education. Educational policies have since become more pragmatic, focusing on measurable efficiency and skills, performance indicators and costing. If we analyse carefully, we realize that services have begun to be outsourced, which has encouraged partnerships and the creation of specialized agencies outside the line ministries.

By making an analysis inspired by the context of neoinstitutionalism, it is noticed that the institutional system of the European Union reflects the model of Stiglitz's principal-agent relationship. This is about a system of transferring sovereignty and delegating powers, which Kassim and Menon (Kassim, Menon 2003) critically evaluate in the context of recent developments. All these thoughts show that the company is moving towards the development of interinstitutional partnership and collaboration concepts and towards greater involvement of the private sector, associations and trade unions in public policy making. 
According to Castells, modern society no longer operates with individuals and autarchic entities but creates a global environment of socialization, inclusion and participation. This new flow-based space tends to replace and dominate the space we have used to date. The first organizes simultaneous interconnected social practices, far away, benefiting from the participation of an unlimited number of social actors. The space of places, centered on proximity and neighborhood, does not have it as such, but it becomes a less important socializing agent. The emphasis is on connections and interdependencies and not on solitary activity of the individual motivated by his own goals and scales of success. The network society, after Castells, puts the flow, exchanges of significance between different locations and interconnected actors in the foreground (Castells 2009).

\section{EDUCATIONAL POLICIES AND PARTNERSHIPS}

The partnerships have stayed, stand and I think they will be the basis for international relations. When we try to define the term of partnership, we have to consider that it takes place between at least two parts. These parties may be constituted by state actors, state and civil society, associative structures and trade unions. All this together creates or can create public policies and educational policies, treaties and laws in international relations.

I will focus on four types of partnerships wich i consider to be the most active and significent for the context of international relations:

a) The alliances, which maintain a high degree of autonomy of the parties, involve association-based participation in a network of communication and cooperation, as are most international relations partnerships.

b) Co-management, involving mandated institutional delegates, such as representatives of the parents' association, in the Board of Directors of the educational establishment;

c) The consortium, which consists of a temporary pooling of the institutions concerned to strengthen its position on the services market 
and to address issues of common interest more effectively; they work on an association basis, and as an example we could discuss intercommunity development associations;

d) The social partnership, which is a social dialogue structure, made between trade unions and employers, plus the representatives of the Government, in the variant of the tripartite partnership; is a highly institutionalized formula at European level, where we can remember the Economic and Social Committee and at the level of the member states, for example the Economic and Social Council of Romania.

There is a great diversity of partnerships as a form of networking for cooperation and communication. Spontaneously or on the initiative of the authorities, with a participation that can engage several institutions or entire sectors of activity, represented in a large-scale structure, inter-institutional partnerships have become an indispensable actor of public policies. It is a natural result of the functional specialization of the institutions, on the one hand, of the need to use resources as efficiently as possible. The spectacular emergence of interinstitutional partnerships confirms the finding that none of the public-space actors, not even the state that seemed omnipotent in the age of modernity, can solve by itself the social problems we face. Europality is the most relevant case of interinstitutional partnerships. What it follows from the analysis so far is that the Europality involves new types of actors and new forms of collective action. International agenda is less dominated by charismatic personalities but is better a space of alliances and permanent collective and for that, the interinstitutional partnerships meet the following conditions that $i$ think will support this analysis:

a) They are institutions with legal personality, not private individuals. According to Scott's classic definition (Scott 2004), institutions are "rules systems that determine human interactions." They are relatively stable, because they allow the realization of certain social functions such as school or university, Parliament, police, customs, hospital or court are indispensable, among other things, so that they are explicitly mentioned in any law regarding their fields of competence. The collective action of the society is organized through the institutional system. Partnerships increase the operational base of the 
institutional system and provide new opportunities for operation and organization (Scott 2004, 296).

b) Benefit from public recognition, which gives them authority and organizational identity. Partnerships act on their own, regulations that may be in the form of law, but also through association agreements, charter or internal regulations. As actors of public space, partnerships are bound to ensure transparency and public accountability.

c) Partnerships are not limited to the juxtaposition of resources. They are nonhierarchical symbolic systems that provide a moral reference framework or what Wenger (1998) calls a "community of practice." It is a community of values and meanings, a social learning space where each participant comes with its organizational history, its own skills and messages. This interinstitutional community is legitimated by its social utility, by the added value of the union to the singular contributions of the participants.

For the international relations perspective, the most suited form of interinstitutional partnership is the alliance. She is based on the affiliation decision of the institution. If we are talking about the degree of autonomy, alliance is preserving the institution's autonomy. If we are talking about regulations, the alliance is characterized by association agreement, valid through the consent of the parties. Also, the organizational identity of an alliance is being a participant in a communication network, without changing its identity.

Erasmus program can be described as one of the most successful European programs due to the large number of teachers, administrative staff and students who benefit from annual exchanges of experience between their universities or faculties.

As we can learn from the official website of the program, Erasmus + is the program by which the EU supports education, training, youth and sport in Europe. It has a budget of EUR 14.7 billion, with the help of which over 4 million Europeans can gain experience and have access to study, training and volunteering abroad. Opportunities are for both individuals and organizations. The budget of the program is EUR 14, 7 billion. More than 4 million people can be involved in this program. There are approximately 2 million students, approximately 800,000 associate professors, teachers, trainers, educational staff 
and youth workers who can benefit by this exchange. There are also, approximately 25000 partnerships bring together 125000 schools, education and training institutions, higher education and adult education institutions, youth organizations and businesses, and over 150 alliances established by 1500 higher education institutions and businesses. Finally, there are over 150 alliances established by 2,000 enterprises and providers of education and training. (https://ec.europa.eu/programmes/erasmus-plus/about/key-figures_ro)

All of this data shows us that Erasmus can be defined as a type of valid partnership that has the characteristics of an alliance. Institutions and people benefiting from the program are alliances and partnerships based on this exchange of good practices meant to lead to organizational development.

The second model of a partnership it is the Co-management. His representativeness it is characterized by pass through elections (or other form of voting) and institutional delegation. Here, the degree of autonomy it is within the limits of the mandate and the regulations are based on a charter or regulations. It is the participant in the management of the organization in which is integrating this overall mission if we are talking about the host institution. Or she can become.

Third model of partnership that $i$ have choosed to talk it is the Consortium. His representativeness it is characterized by decision of the management of the institutions and by voluntary participation and collegial type. His degree of autonomy is represented by participating institutions whom they are coordinating their policies, but they maintain the autonomy and authority of their own leadership and the regulations are made in terms of the cooperation agreement, complemented by reciprocal service contracts and sharing of resources. Consortium has a new organizational identity, obtained through the participants cumulated image and resources.

The last type of a partnership is the Social partnership who is representing large categories and sectors of activity who choose representatives in partner structures at local, regional and national level. Delegation of authority is in the form of representation mandate. The institutions represented retain their autonomy, but the participants become partners or members of a corporation. It is also characterized by a double loyalty to institutions of origin and 
partnership. The regulations are characterized by labor law and related policies (social protection, vocational training, regional development), by ad-hoc regulations (for internal use) and informal consensus among partners.

In my doctoral research, I have used a questionnaire to find some answers to the general question regarding the organizational culture of partnerships and its role in international relationships. The questionnaire was addressed to pupils, students, representatives of parents and managers of educational institutions. More concretely, it addressed particular aspects of partnerships between trade unions, educational institutions, representative associations of pupils, students or representatives of parents and educational institutions.

The first question concerned the decision making process within the bodies or organizations of which the respondents are involved. The question was addressed mainly to educational institutions managers (see the graph, herewith). The blue chart is represented by expresion "most often", the red is "often", orange is middle, the green color means "few times" and the purple means "never".

The blue chart indicating that most of the time, within an educational institution, the decisions are taken by the Board of Directors, at first glance we can interpret as an institutional body that makes the decisions most often in within an institution. But at the same time, I could consider the Board of Directors as a model of partnership within the institution, especially because it includes delegates from local authorities, school manager, teachers, parents, and even student representatives as guest.

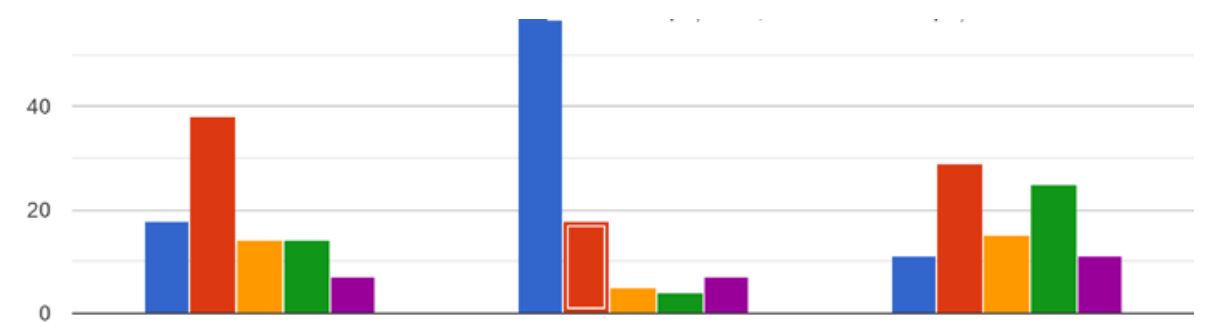


Besides this, we can see that in the institutions, the role of the leader or his representative is an essential one. As the first graph shows, the one on the left, we notice that most of the decisions are taken by the leader.

In the last graph, the one on the right, we can see that most of the decisions are taken with the help of other institutions or bodies. From this we deduce the fact that there is a desire to create partnerships with other structures or institutions, and even we can say that for some time there is a organizational culture based on partnerships within the public institutions.

No institution or organization can operate without a regulatory framework. Most of the time, they operate on the basis of a minister's order, a regulation of organization and functioning or a statute. I have considered the question below about regulatory initiatives or the regulatory framework of the organization, having to find out what the degree of involvement of respondents in this topic is. I believe that every member of a team or employee of an institution could contribute to the creation of a set of regulations designed to improve the activity and conditions within the organization. As we can see in the graph below, there is little difference between respondents who are involved in creating such regulations and those who do so. In this figure, those people who answered with Yes are represented by blue color, and those who answered with NO are represented by red color.

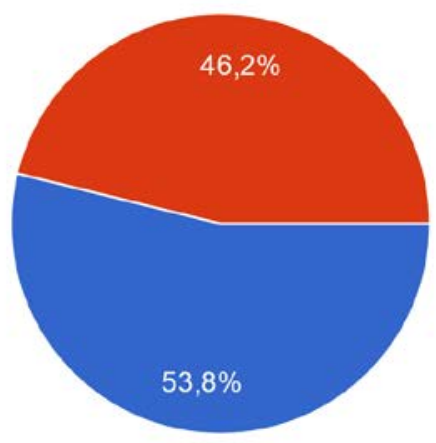


No partnership can take place without an active participation in the types of decisions that are made within an organization. As I have noted above, given that decisions are mostly taken by the management, it seemed important to find out if the people who are present at the meetings of the management of the organizations consider their involvement and participation to be beneficial. As we can see, in the figure that has the question "Your participation in the meetings of the leadership of your organization influenced the decisions of the organization / institution / favored institutional development? And analysing the chart we realize that the opinions and active participation of the interviewed persons influenced the decisions made within the organization, even to a small extent. We need to check here red, orange and green colors. From blue to purple, the meanings are from less to decisive.

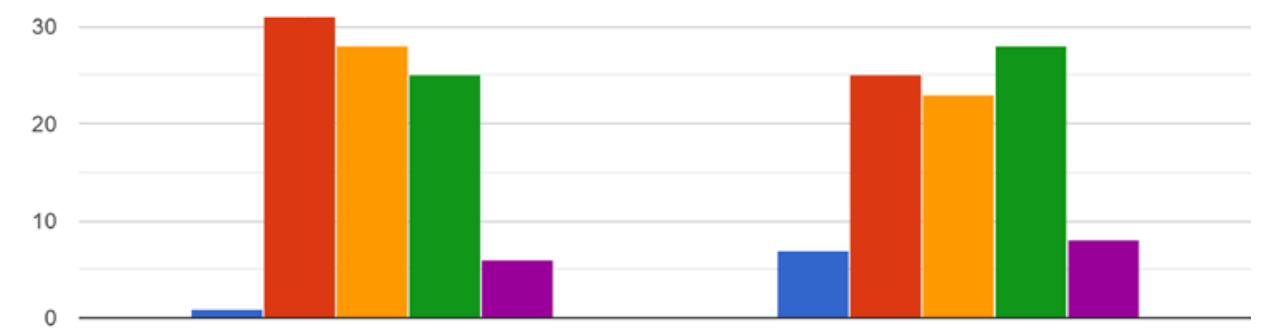

When asked about the forms of institutional partnership in which your organization participates, the $72 \%$ respondents chose the public-private partnership. Looking at this aspect, we can see that, both at national and international level, partnerships between public and private institutions are the largest interes. Over time, the state played the largest role in the development of society. Often, even the one. Along with the first types of state organization with the help of democracy, other forms of collaboration, in the beginning, of the representatives of the state governments with different people, have emerged, reaching to this public-private interinstitutional collaboration.

As can be seen in the figure below, the question "To what extent are interinstitutional partnerships contributing to the development of the quality of the activities carried out in your institution?", about $79 \%$ of respondents have 
shown that interinstitutional partnerships are largely conducive to organizational development. The blue part represents aproximative $18 \%$. Those are the respondents who think that interinstitutional partnerships contributing to a small extent on development their institution.

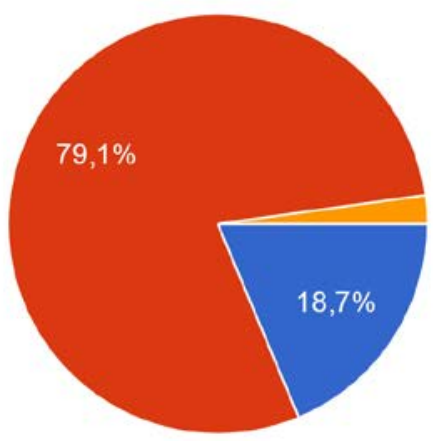

The main problem that may argue within this model of educational policy variants that many contemporaries see as the best, I refer here to Partnershipbased Governance is the risk that state actors or government representatives have the same priorities as civil society representatives. As is the case with international relations, when you create a partnership or a policy, some parties have more to gain and others have to cede certain aspects. This is also the case within the Government where, many times, what civil society considers and regards as something very easy to accomplish, state representatives, with important and truthful arguments, proves that it is harder or even impossible to achieve.

Schooling is, in my opinion, one of the goals that each society should consider to be the main one. At the grassroots level, there is an alarming rate of school absenteeism and even school dropout. There are studies that show us that the situation is alarming in states in South East Europe and especially in Africa. There are world bodies such as the UN or UNICEF who have created 
partnerships and even policies with state actors to try to identify the causes of this worrying and especially trying to come up with solutions. Even in Romania there are alternative programs to combat school absenteeism and school dropout. These programs are based on cultural, artistic and sporting activities designed to discover pupils' special skills. These often take place in educational institutions, precisely to attract students and to make them want to spend time in school.

In the field of international relations, most interinstitutional partnerships are in the form of alliances, following the model described above. Waddell and Klagram (Waddel, Klagram 2007) explained this situation through the action of the principle of sovereignty and the prevalence of intergovernmental law, which limits, in fact, the possibilities of international integration. Even in the context of the European Union, where Community law acts and sovereignty has its own manifestation, alliances are the most common interinstitutional arrangement. We can illustrate this trend by analysing three successful European programs dedicated to major fields of activity, namely education, science and culture. I am referring here to the Erasmus, Cost and Creative Europe programs. They can be analysed on the basis of the matrix who is refering at type of partnership, implementation study and some statistic dates, with concrete reference to the four criteria, namely representativeness, degree of autonomy, regulation and organizational identity.

\section{CONCLUSIONS}

Each institutionalized system is well established. In democracy, state institutions are meant and are encouraged to work together. There can be no education system without economics, there can be no market-orientated production and there can be no ministries without government. Certainly, since the formation of the modern state, the institutions have had to obey state finances. In education, as with any other type of public policy, initiative or action, budget allocations are needed to meet the needs of citizens. I believe that one of the major problems of the education system in Romania and beyond is represented by under- 
financing. Educational policies developed, developed and implemented through partnerships are certainly an alternative to classical policy on the hierarchical scale of law enforcement.

The society must be in a continuous development. Educational systems must keep up with the dynamics of intellectual development of youth. Technologies are developed along with education, and education systems can also be developed with the help of technology. The current generation of students need a school to attract them, which will make them want to spend their time within the classroom. If the educational system is able to keep up with the needs, requirements and qualities of the new generations, society in the future will only gain.

The future of education will probably be described by the phrase "a different education" centered on the pupil but produced by teachers with the help of civil society, associative structures in the field and even with the direct involvement of pupils and students. The main bearers of the education system can become the main source of ideas for responding to their needs. And at the same time, the needs of teachers also. All society is based on education and these answers can be found through the partnership of all the actors involved there.

International relations are a dynamic field. The rules that guide them, the diplomacy, the politics and the citizens' needs are constantly changing and developing. For the best results, the field of international relations is based on partnerships. Some partnerships are civil, other institutional, interinstitutional and partnerships between individuals and organizations. At the same time, the partnership between decision-makers and non-governmental organizations is a very important one in the field of international relations. As Europe is on the move, partnerships between states are on the rise. Only with good communication and many exchanges of good practices, society can develop and change for the better. 


\section{REFERENCES}

- Bîrzea, Cezar. 2010. „Partnerships and Networking in Education”. Paper presented at the Council of Europe Standing Conference of Ministers of Education, Ljubljana, 4-5 June.

- Castells, Manuel. 2009. Communication Power. Oxford/New York: Oxford University Press.

- Erasmus Plus statistics. European Commission. https://ec.europa.eu/programmes/erasmus-plus/about/statistics_ro.

- Kassim, H; Menon, 2003. „The principal-agent approach and the study of the European Union: promise unfulfilled?". Journal of European Public Policy. 10:1. 121-139. DOI: 10.1080/1350176032000046976.

- Kok, W. 2004. Embracing the change. Lisbon Strategy for Growth and Jobs. Brussels. European Communities.

- Rosati, D.K. 1998. Economic Disparities in Eastern Europe and the Impact of EU Enlargement. Geneva. UN Economic Commission for Europe and Central European Initiative.

- Scott, R.W.2004. Institutions and organizations. Iasi: Polirom.

- The European Semester. European Commission. http://ec.europa.eu/europe2020/index_en.html.

- Waddell, S.; Klagram, S. 2007. „Multi-stakeholder Global Networks: Emerging Systems for the Global Common Good" In: P. Glasbergen, F. Biermann, A.P.J. Mol (eds) Parterships, Governance and Sustainable Development: Reflections on Theory and Practice, Cheltenham Glos, Edward Elgar Publishing, 261-287. 